\title{
High Power Factor in Three-phase Voltage Source Pulse-Width Modula- tion Rectifier Based on Direct Power Control
}

\author{
Bo Fan $^{1,2, *}$ and Shuzhong Song ${ }^{1}$ \\ ${ }^{\text {I}}$ Electronic \& Information Engineering College, Henan University of Science and Technology, Luoyang 471003, China \\ ${ }^{2}$ Citic Heavy Industries Co., Ltd. Luoyang 471003, China
}

\begin{abstract}
The conventional pulse-width modulation rectifier has the low power factor and more sensors to detect the voltage and current of alternating current side. The traditional direct power control method possesses the defect of unfixed switching frequency. A new method based on three-phase voltage source pulse-width modulation rectifier with high power factor based on direct power control is proposed in this paper. With the analysis of the formation mechanism of the switch table, the stationary coordinate is divided into 12 vectors to optimize the input voltages. Virtual flux estimator is introduced to replace voltage sensors. Instantaneous power theory is used to calculate the estimated virtual flux active and reactive power with outer voltage and inner power loop control mode. The direct power control strategy of space vector modulation is introduced to provide the fixed switching frequency on pulse-width modulation. The experimental results show that the direct power control system has good dynamic response, so as to achieve active power and reactive power control, which ensures that the input side of the unity power factor control. It is illustrated that this method can achieve higher power factor and total lower harmonic disturbance than the conventional current control strategy.
\end{abstract}

Keywords: Direct Power Control, Power Factor, Pulse-width modulation rectifier, Virtual Flux.

\section{INTRODUCTION}

The usage of a diode bridge circuit in there-phase rectifiers is simple, robust, and low in cost, however, it has various disadvantages such as, unidirectional power flow, low power factor, high level of harmonic input currents etc [1]. Therefore, research on three-phase rectifiers (converters) has grown rapidly over the past few years due to some of their important advantages, including power regeneration capabilities, control of Dc-bus voltage, low harmonic distortion of input currents, and high power factor (usually, near unity) [2-5].

The pulse-width modulation (PWM) rectifier has the advantages, such as constant direct curent (DC) voltage control, low harmonics of the grid side current, energy double-diretional flow, to apply widely in rectification, active filtering, reactive power compensation and alternating current (AC) drive systems. The control strategies of PWM rectifier include indirect current control, direct current control and direct power control (DPC)[6-10]. In order to obtain the high power factor and near-sinusoidal current waveforms, various control strategies have been proposed in the recent work on this type of PWM converter.

DPC system was proposed by Tokuo Ohnishi in the early 90 s of $20^{\text {th }}$ century, and was obtained through further study by Toshihiko Noguchi [11]. DPC is based on the instantaneous active and reactive power control loops, which

*Address correspondence to this author at the Electronic \& Information Engineering College, Henan University of Science and Technology, Luoyang 471003, China; Tel: +86-18637908501;

E-mail: fanbo box@hotmail.com has the simple algorithm and structure and low THD. The traditional DPC uses hysteresis regulator and selects voltage vectors while considering the lookup table. Its advantages do not need to rotate the coordinate transformation, simple control structrure and fast dynamic responses. However, this method has the disadvantages including switching frequency unfixed, the requirement of fast processor and $\mathrm{A} / \mathrm{D}$ transducer $[12,13]$, which are difficult to realize in the industrial applications. Additionally, there is no internal current control in the DPC.

In PWM rectifier control stategies, traditional voltage oriented method is used for multiple sensors as the its circuit structure is complex and it undergoes big error. The virtual grid flux oriented method not only saves the grid voltage sensors, but the virtual flux (VF) accurate estimation also has a good inhibitory effect on the interference signal of the measurement.

This paper presents a new method of PWM rectifier DPC with SVPWM based on VF. By means of instantaneous reactive power theory, reactive power and active power are calculated. The VF oriented is adopted to DPC system. With theoretical voltage sector and switching state selection, space vector modulation (SVM) regulator is introduced in DPC to replace the hysteresis regulator. Simulation and experiment will verify the characteristics of the proposed method.

\section{THE MATHMATICAL MODEL OF BOOST-TYPE PWM RECTIFIER}

The three phase Boost-type PWM recitfier topology is shown in Fig. (1), in which $R$ and $L$ represent the stator resistance and the stator leakage inductance of the virtual 


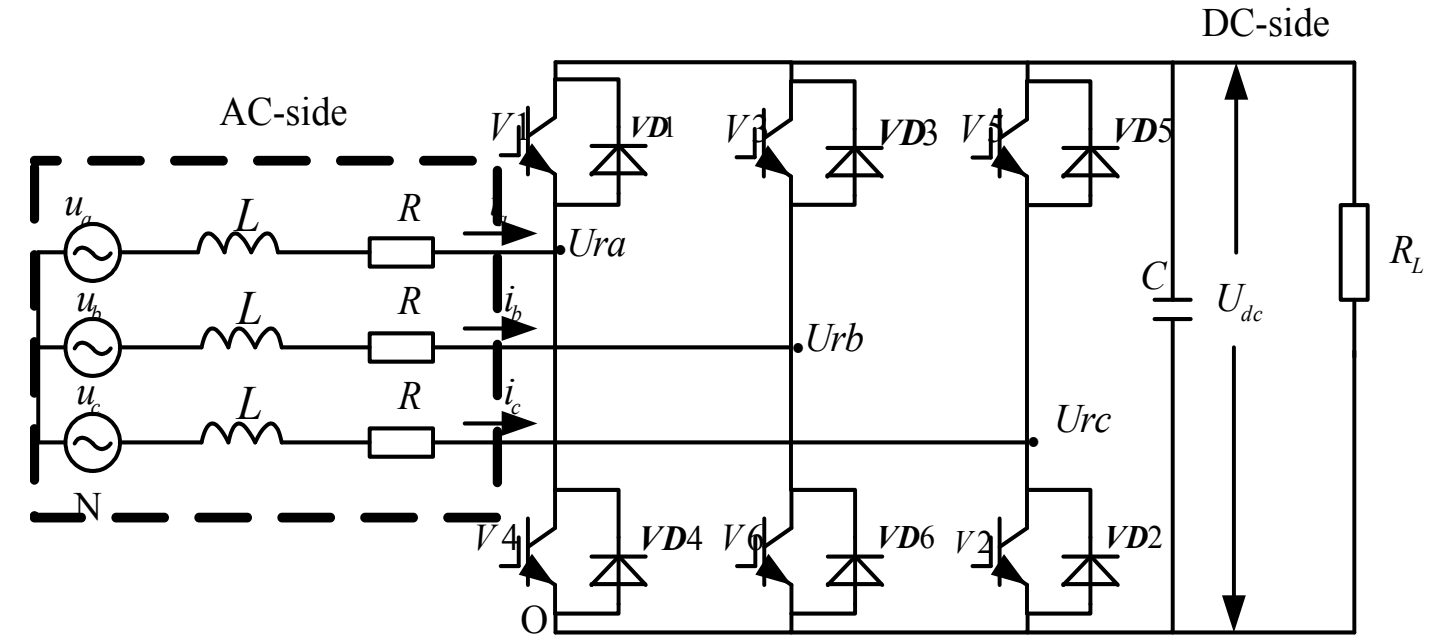

Fig. (1). Main circuit of Boost-type PWM rectifier.

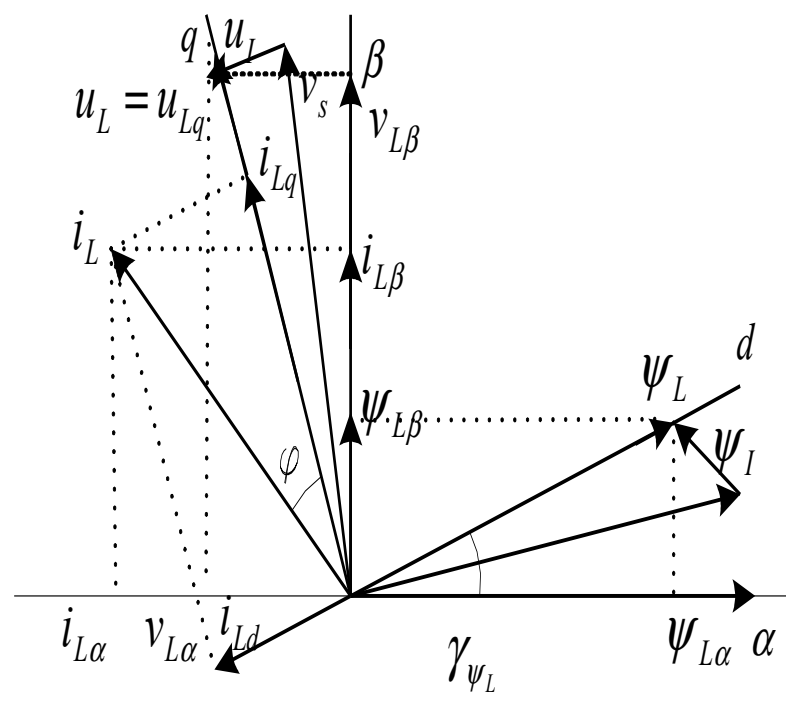

Fig. (2). Relationship between VF and line voltage in stationary $\alpha \beta$ coordinates.

motor $; u_{a}, u_{b}, \quad u_{c}$ are line-to-line voltage, respectively; $I_{a}$, $I_{b}, \quad I_{c}$ are grid side current, respectively; $R_{L}$ is the load resistance; and $C$ is the smoothing capacitor.

The mathematical model of two-phase stationary $(\alpha \beta)$ coordinates is as follows:

$\left[\begin{array}{c}u_{\alpha}(k) \\ u_{\beta}(k)\end{array}\right]=\frac{L}{T}\left[\begin{array}{c}i_{\alpha}-i_{\alpha}(k-1) \\ i_{\beta}-i_{\beta}(k-1)\end{array}\right]+\left[\begin{array}{c}u_{s \beta} \\ u_{s \beta}\end{array}\right]$

The mathematical model of two-phase rotating $(d q)$ coordinates is as follows:

$\left[\begin{array}{c}u_{d}(k) \\ u_{q}(k)\end{array}\right]=\frac{L}{T}\left[\begin{array}{c}i_{d}-i_{d}(k-1) \\ i_{q}-i_{q}(k-1)\end{array}\right]-\omega L\left[\begin{array}{c}i_{q}(k) \\ i_{d}(k)\end{array}\right]+\left[\begin{array}{c}u_{s \beta} \\ u_{s \beta}\end{array}\right](2)$

where, $k$ is the sampling time, $T$ is the sampling period, $u_{\alpha}(k), u_{\beta}(k), i_{\alpha}(k), i_{\beta}(k)$ are supply volatge and current values of the $k$ sampling cycle in two-phase stationary $(\alpha \beta)$ coordinates, and $u_{d}(k), u_{q}(k), i_{d}(k), i_{q}(k)$ are supply volatge and current values of the $k$ sampling cycle in two-phase rotating $(d q)$ coordinates, $u_{s \alpha}(k), u_{s \beta}(k), u_{s d}(k), u_{s q}(k)$ are input voltage values of the $k$ sampling cycle in $(\alpha \beta)$ coordinates and $(d q)$ coordinates, respectively.

\section{POWER ESTIMATION BASED ON VIRTUAL FLUX}

DPC is based on the instantaneous active and reactive power control loops. Because the converter switching states are selected by a switching table, which is based on the instantaneous errors between the commanded and estimated values of active and reactive power, there are no internal current control loops and no PWM modulator block in DPC system [7, 8]. Therefore, the key point of the DPC implementation is a correct and fast estimation of the active and reactive power line power. 


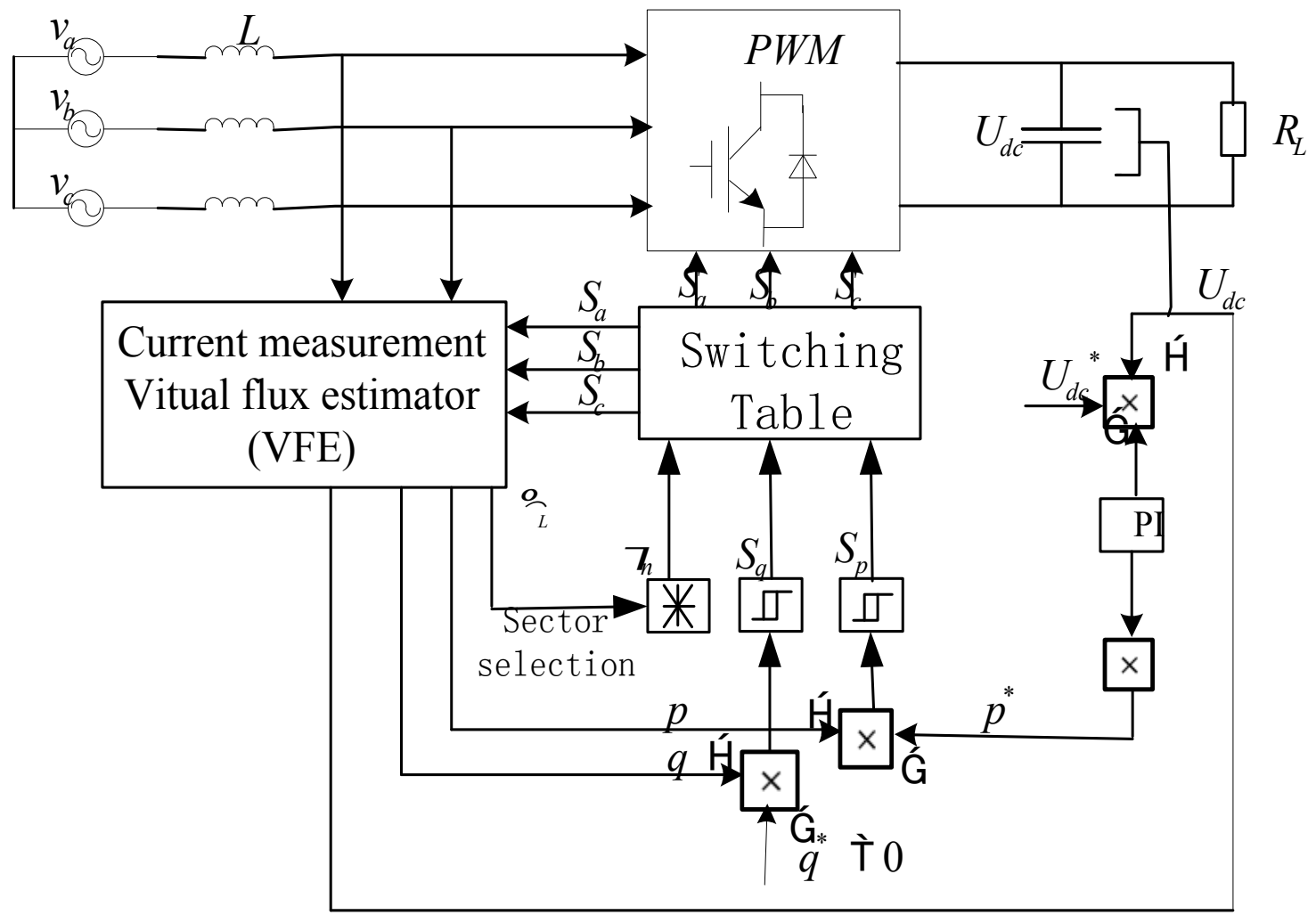

Fig. (3). Configuration of VF-DPC.

\subsection{Estimation of Virtual Flux}

With VF observer instead of AC side voltage sensors, PWM rectifier device reduces its volume, saves the cost, and realizes the isolation of main circuit and control circuit. Also, this method can impove power factor and reliability etc. VF is considered as the phase reference point. The concept of $\mathrm{VF}$ originates from the virtual generator. As shown in Fig. (2), the gridlines part in diagram is seen as $\mathrm{AC}$ motor, and are the virtual motor stator resistance and leakage inductance. The line voltage is generated by virtual air gap flux induction. The virtual flux is behind virtual induction electromotive force of 90 electrical degrees. The relationship between the VF and line voltage in a two-phase stationary $\alpha \beta$ coordinates system is shown in Fig. (3).

Where:

$\psi_{L}-\mathrm{VF}$ vector of line;

$v_{s}$-converter voltage vector;

$u_{L}$-line voltage vector;

$u_{\mathrm{I}}$-inductance voltage vector;

$i_{L}$-line current vector.

With the definitions: $\psi_{L}=\int u_{L} d t$, thus:

$u_{L}=\left[\begin{array}{l}u_{L \alpha} \\ u_{L \beta}\end{array}\right]=\sqrt{\frac{2}{3}}\left[\begin{array}{cc}1 & 1 / 2 \\ 0 & \sqrt{3} / 2\end{array}\right]\left[\begin{array}{l}u_{a b} \\ u_{b c}\end{array}\right]$
$\psi_{L}=\left[\begin{array}{l}\psi_{L \alpha} \\ \psi_{L \alpha}\end{array}\right]=\left[\begin{array}{l}\int u_{L \alpha} d t \\ \int u_{L \beta} d t\end{array}\right]$

Based on the measured DC-link voltage $U_{d c}$ and the duty cycles of modulator $S_{a}, S_{b}, \quad S_{c}$ the virtual flux $\psi_{L}$ components are calculated in stationary $(\alpha \beta)$ coordinates system as follows:

$u_{s}=\left[\begin{array}{l}u_{s \alpha} \\ u_{s \beta}\end{array}\right]=U_{d c}\left[\begin{array}{ccc}\frac{2}{3} & -\frac{1}{3} & -\frac{1}{3} \\ 0 & \frac{1}{\sqrt{3}} & -\frac{1}{\sqrt{3}}\end{array}\right]\left[\begin{array}{l}S_{a} \\ S_{b} \\ S_{c}\end{array}\right]$

$R$ can be neglected, AC side voltage equation is:

$u_{L}=u_{s}+u_{l}\left\{\begin{array}{l}L \frac{d i_{\alpha}}{d t}+u_{r \alpha}=u_{L \alpha} \\ L \frac{d i_{\beta}}{d t}+u_{r \beta}=u_{L \beta}\end{array}\right.$
$\psi_{L}=\psi_{s}+\psi_{l}\left\{\begin{array}{l}\psi_{L a}=L i_{a}+\int u_{s \alpha} d t \\ \psi_{L \beta}=L i_{\beta}+\int u_{s \beta} d t\end{array}\right.$

\subsection{Active and Reactive Power Estimator}

Using complex notation, the instantaneous power can be calculated as follows: 


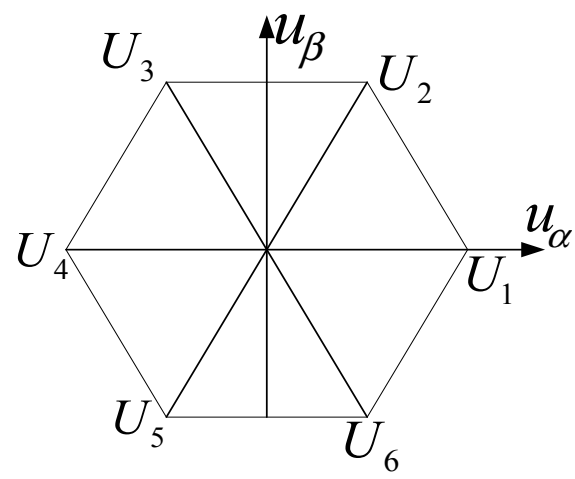

Fig. (4). Space vectors of DPC system.

$\left\{\begin{array}{l}p=\mathrm{R}_{\mathrm{e}}\left(u_{L} \cdot \overline{i_{L}}\right) \\ q=\mathrm{I}_{\mathrm{m}}\left(u_{L} \cdot \overline{i_{L}}\right)\end{array}\right.$

Line current vector is:

$i_{L}=\left[\begin{array}{l}i_{L \alpha} \\ i_{L \beta}\end{array}\right]=\sqrt{\frac{2}{3}}\left[\begin{array}{cc}\frac{3}{2} & 0 \\ \frac{\sqrt{3}}{2} & \sqrt{3}\end{array}\right]\left[\begin{array}{l}i_{a} \\ i_{b}\end{array}\right]$

Where $i_{L}$ denotes conjugate of the line current vector. The line voltage can be expressed by the VF as

$u_{L}=\frac{d}{d t} \psi_{L}=\frac{d}{d t}\left(\left|\psi_{L}\right| e^{j \omega t}\right)=\frac{d\left|\psi_{L}\right|}{d t} e^{j \omega t}+j \omega \psi_{L}$

If the line voltage are assumed to be sinusoidal and balanced, the derivatives of the flux amplitudes are zero. The instantaneous active and reactive powers can be reduced as

$$
\left\{\begin{array}{l}
p=\omega\left(\psi_{L \alpha} i_{L \beta}-\psi_{L \beta} i_{L \alpha}\right) \\
q=\omega\left(\psi_{L \alpha} i_{L \alpha}+\psi_{L \beta} i_{L \beta}\right)
\end{array}\right.
$$

\section{DPC SYSTEM WITH SPACE VECTOR MODULA- TION BASED ON VIRTUAL FLUX}

The DPC system based on VF is shown in Fig. (3). the active power $p$ and active power $q$ are obtained by VF and power estimation. $p$ and $q$ are compared with the given value $p^{*}$ and $q^{*}$. These comparison results are put into power hysteresis comparator to acquire the reflected power offset switching quantities, which are used to select switching table variable with sector selection signals. Therefore, the fast and accurate VF and power estimation are very important.

\subsection{Principle of DPC and the Value of $S_{p}$ and $S_{q}$}

Based on the measured DC-link voltage $U_{d c}$ and the present switch states $S_{a}, S_{b}$ and $S_{c}$, the next switch states are derived. The active power command $p^{*}$ is provided from a dc-bus voltage control block, while the reactive power command $q^{*}$ is directly given from the outside of the controller $\left(q^{*}\right.$ is set to 0 , to achieve unity power factor control). Errors between the commands and the estimated feedback power are input to the hysteretic comparators and digitized to the signals $S_{p}$ and $S_{q}$, whereas the digitized error signals $S_{p}, S_{q}$ and the line voltage vector position $\gamma_{U L}=$ $\operatorname{arctg}\left(u_{L \beta} / u_{L \beta}\right)$ are input to the switching table in which every switching state $S_{a}, S_{b}$ and $S_{c}$, of the converter is stored in a switching table, then by accessing the address of the lookup table the appropriate voltage vector is selected from a switching table.

The digitized output signal of the active power $S_{p}$ and reactive power $S_{q}$ controller are defined as:

$S_{p}= \begin{cases}1 & p<p_{r e f}-H_{p} \\ 0 & p>p_{r e f}+H_{p}\end{cases}$
$S_{q}= \begin{cases}1 & q<q_{r e f}-H_{q} \\ 0 & q>q_{r e f}+H_{q}\end{cases}$

Where, $H_{p}$, and $H_{q}$ are the hysteretic band, which determines the control precision and the rectifier switching frequency.

\subsection{Switching Table}

The switch states $\mathrm{S}_{\mathrm{a}}, \mathrm{S}_{\mathrm{b}}, \mathrm{S}_{\mathrm{c}}$ of DPC system are determined on the basis of (7) and (8). The values $\left(\mathrm{S}_{\mathrm{a}}, \mathrm{S}_{\mathrm{b}}, \mathrm{S}_{\mathrm{c}}\right)$ depend on $U_{r}$, which are the discrete values of $U_{0}, U_{1}, U_{2}, \ldots, U_{7}$. $\left(\mathrm{S}_{\mathrm{a}}, \mathrm{S}_{\mathrm{b}}, \mathrm{S}_{\mathrm{c}}\right)$ and $\mathrm{U}_{\mathrm{dc}}$ determines the value of $\mathrm{U}_{\mathrm{r}}$. $\left(\mathrm{S}_{\mathrm{a}}, \mathrm{S}_{\mathrm{b}}, \mathrm{S}_{\mathrm{c}}\right.$ $=000-111)$ corresponds to $U_{0}-U_{7}$ as: $U_{0}(000), U_{1}(100)$, $\mathrm{U}_{2}(110), \mathrm{U}_{3}(010), \mathrm{U}_{4}(011), \mathrm{U}_{5}(001), \mathrm{U}_{6}(101)$, and $\mathrm{U}_{7}(111)$.

$\left|u_{r}\right|=\left\{\begin{array}{cc}\sqrt{\frac{2}{3}} U_{d c} & \left(U_{1} \ldots U_{7}\right) \\ 0 & U_{0} \operatorname{or}_{7}\end{array}\right.$

Vector distribution is shown in Fig. (4). 


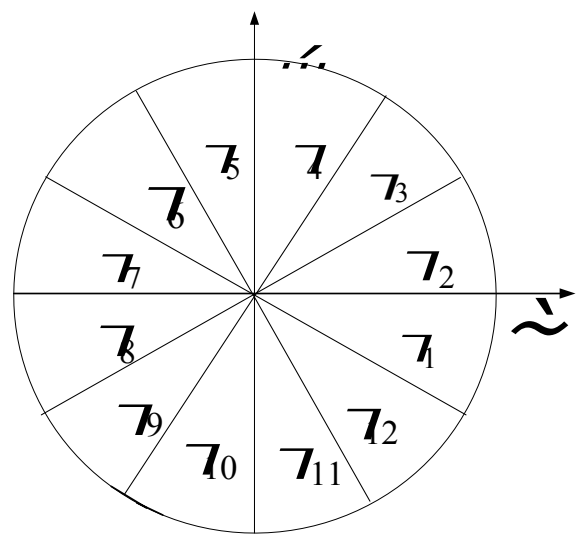

Fig. (5). Twelve sectors on stationary coordinates to specify voltage vector.

Table 1. Switching table for direct instantaneous power control.

\begin{tabular}{|c|c|c|c|c|c|c|c|c|c|c|c|c|}
\hline $\mathbf{S}_{\mathbf{p}}$ & $\mathbf{S}_{\mathbf{q}}$ & $\boldsymbol{\theta}_{\mathbf{1}}$ & $\boldsymbol{\theta}_{\mathbf{2}}$ & $\boldsymbol{\theta}_{\mathbf{3}}$ & $\boldsymbol{\theta}_{\mathbf{4}}$ & $\boldsymbol{\theta}_{\mathbf{6}}$ & $\boldsymbol{\theta}_{\mathbf{7}}$ & $\boldsymbol{\theta}_{\mathbf{8}}$ & $\boldsymbol{\theta}_{\mathbf{9}}$ & $\boldsymbol{\theta}_{\mathbf{1 0}}$ & $\boldsymbol{\theta}_{\mathbf{1 1}}$ & $\boldsymbol{\theta}_{\mathbf{1 2}}$ \\
\hline \hline 1 & 0 & 101 & 111 & 100 & 000 & 111 & 010 & 000 & 011 & 111 & 001 & 000 \\
\hline 1 & 1 & 111 & 111 & 000 & 000 & 111 & 000 & 000 & 111 & 111 & 000 & 000 \\
\hline 0 & 0 & 101 & 100 & 100 & 110 & 010 & 010 & 011 & 011 & 001 & 001 & 101 \\
\hline 0 & 1 & 100 & 100 & 100 & 100 & 100 & 100 & 100 & 100 & 100 & 100 & 100 \\
\hline
\end{tabular}

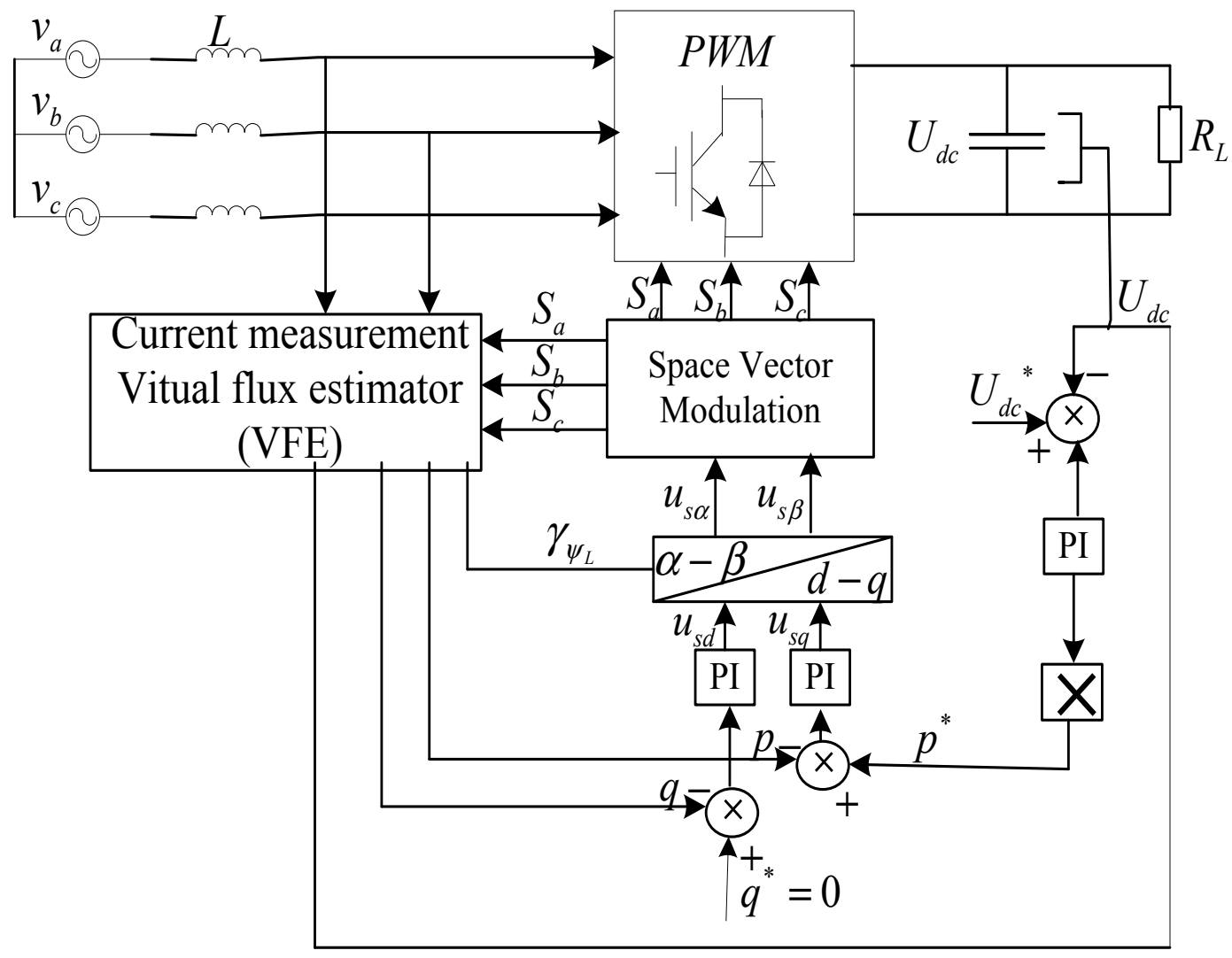

Fig. (6). Block scheme of DPC-SVM. 


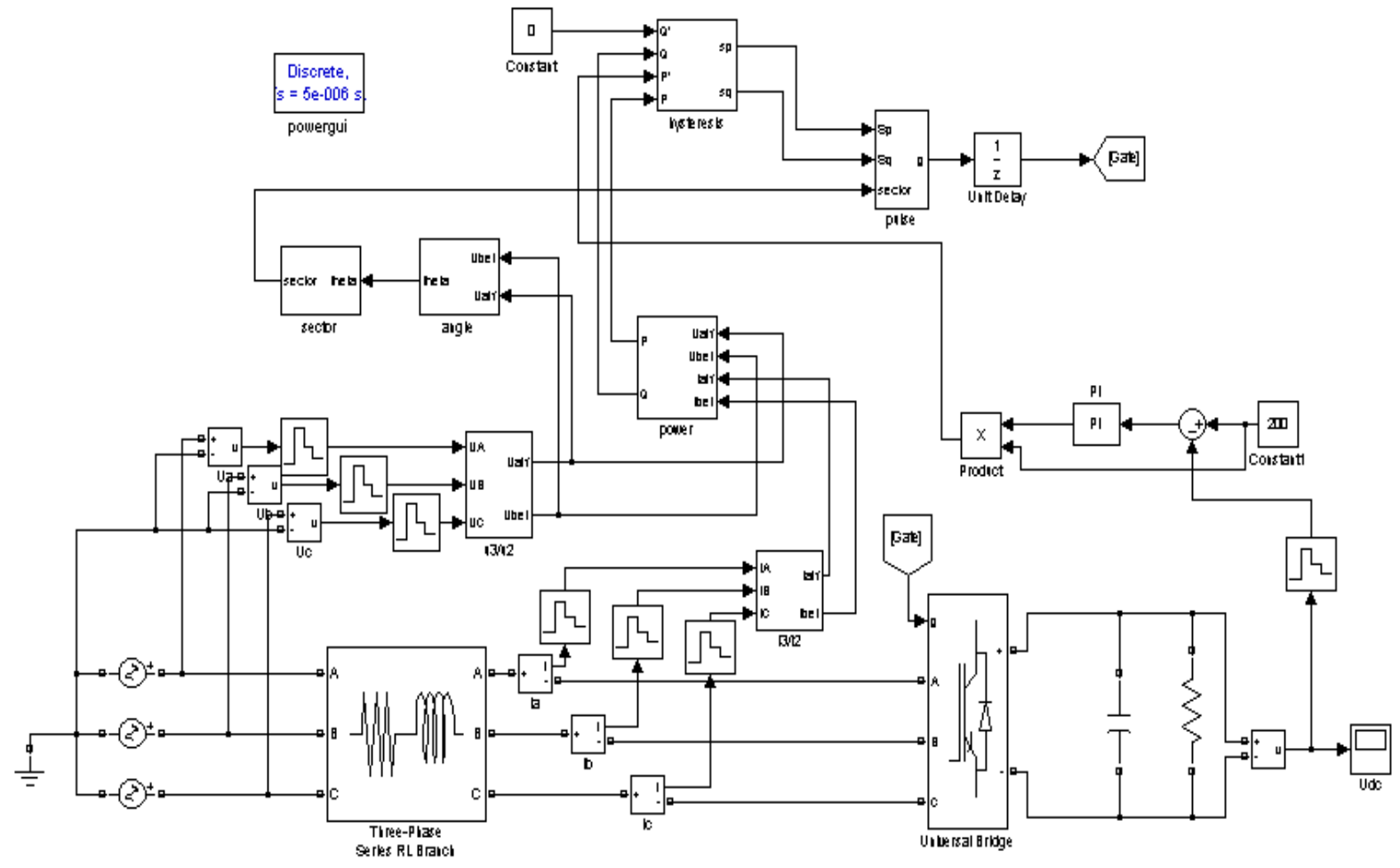

Fig. (7). The Matlab/Simulink platform of DPC-SVPWM based on VF.

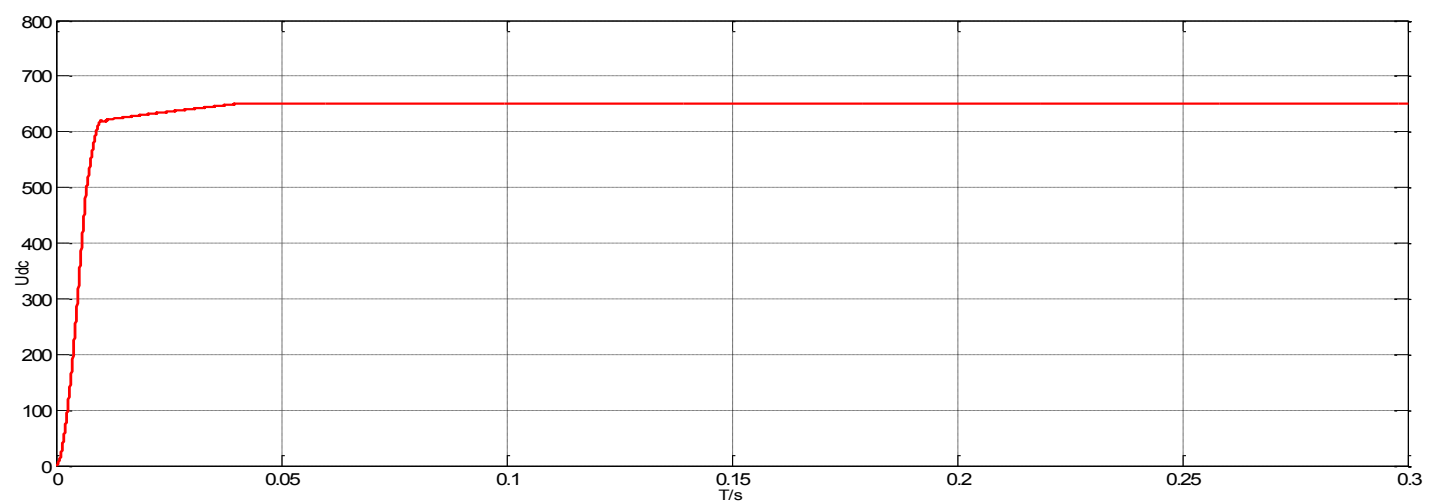

Fig. (8a). DC-link voltage waveform.

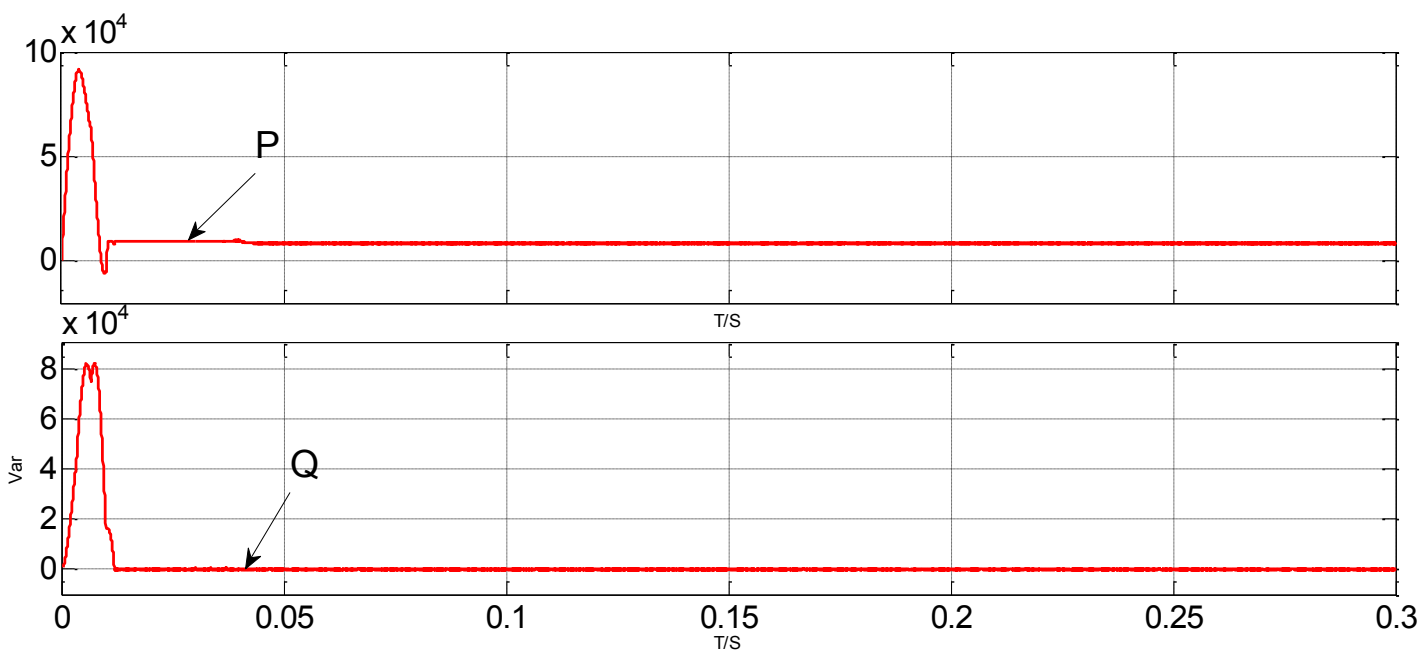

Fig. (8b). Instantaneous active power and reactive power waveform. 

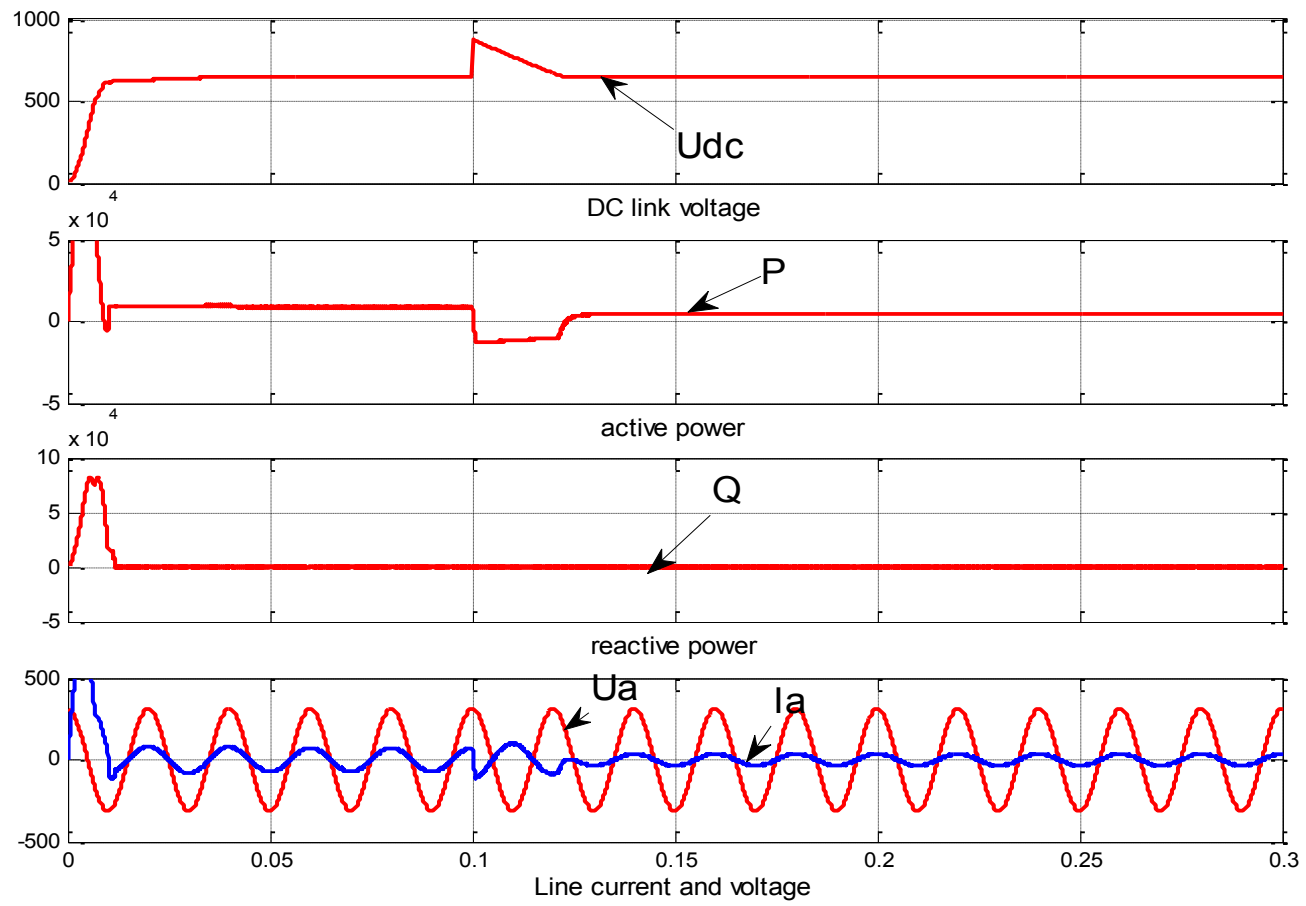

Fig. (8c). Transient test results of the power step change of $\mathrm{p}=8 \mathrm{kw}$ to $2 \mathrm{kw}$.
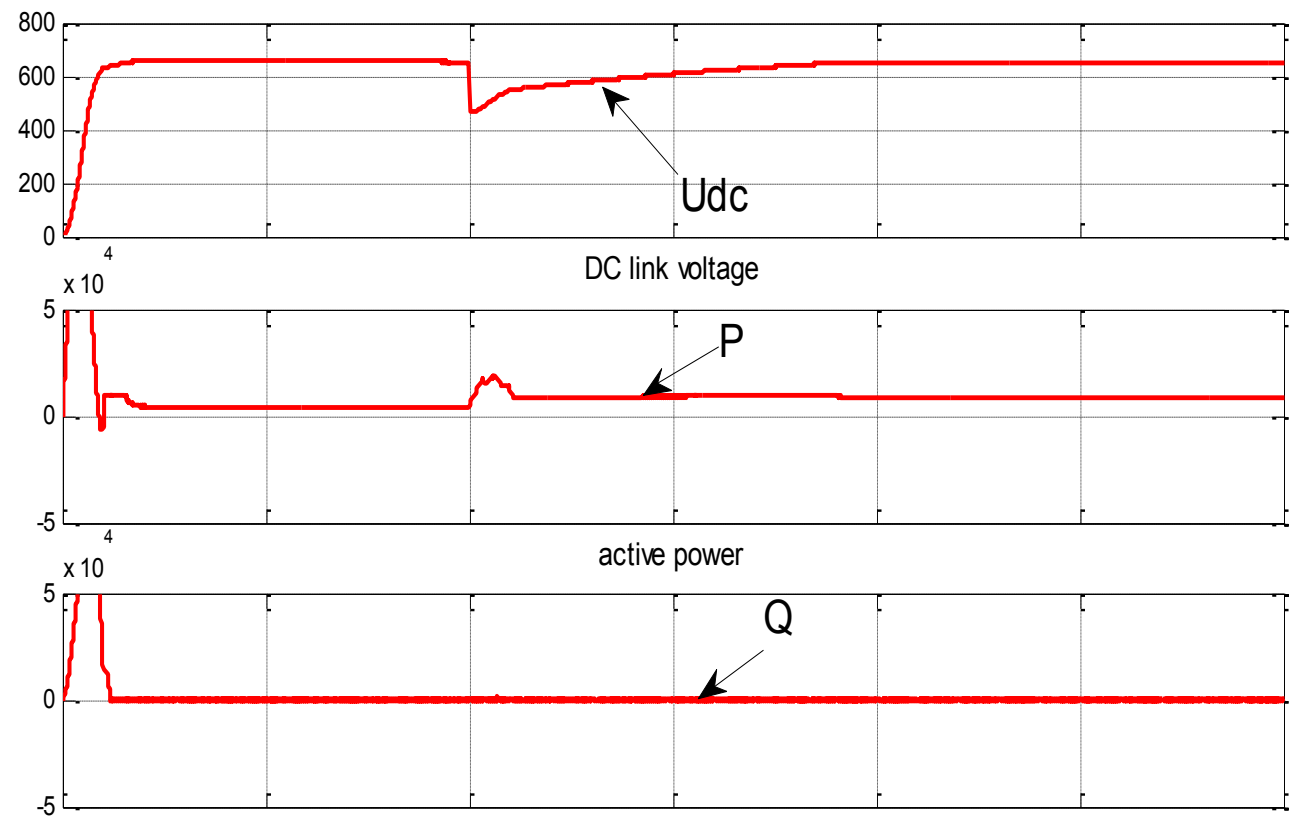

reactive power

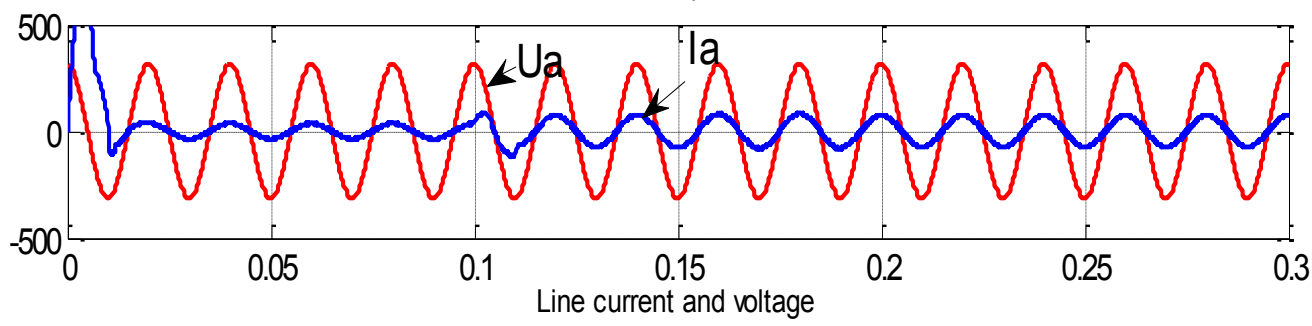

Fig. (8d). Transient test results of the power step change of $p=2 k w$ to $8 k w$. 
In order to optimize the rectifier input voltage vector, the stationary coordinates are divided into 12 sectors, as shown in Fig. (5), $\left(\theta_{\mathrm{n}}=\operatorname{arctgu}_{\beta} / \mathrm{u}_{\alpha}\right)$ and the sectors can be expressed as:

$$
(n-2) \pi / 6 \leq \theta_{n} \leq(n-1) \pi / 6 \quad n=1,2, \cdots, 12
$$

Table $\mathbf{1}$ is a switching table of VF-DPC, Table $\mathbf{1}$ sets the zero space vectors to reduce the frequency and switch off the load and power without energy exchange.

\subsection{DPC with Space Vector Modulation}

Derived from the conventional three-phase Boost-type PWM rectifier DPC system, the control configuration of DPC with space vector modulation system is built as shown in Fig. (6). Different from the traditional VF-DPC, for PWM devices, space vector modulation (SVM) is adopted in DPC instead of switching logic table.

The instantaneous active and reactive power estimation values $p$ and $q$ with the given $p^{*}$ and $q^{*}$, respectively are compared and input to PI regulator, to obtain the rectifier input voltage $(d q)$ coordinates value $u_{s d}$ and $u_{s q}$. They are transformed to $(\alpha \beta)$ coordinates values $u_{s \alpha}$ and $u_{s \beta}$. The equation is as follows:

$$
\left[\begin{array}{c}
u_{s \alpha} \\
u_{s \beta}
\end{array}\right]=\left[\begin{array}{cc}
-\sin \gamma_{\psi_{L}} & -\cos \gamma_{\psi_{L}} \\
\cos \gamma_{\psi_{L}} & \sin \gamma_{\psi_{L}}
\end{array}\right]\left[\begin{array}{c}
u_{s p} \\
u_{s q}
\end{array}\right]
$$

where, $\gamma_{\psi L}=\arctan \left(\psi_{\alpha} / \psi_{\beta}\right)$ is a vector angle of VF under twophase stationary $(\alpha \beta)$ coordinates.

Finally, the space vector modulation is used to obtain the PWM switching signals, which control the power devices in a rectifier.

\section{EXPERIMENTAL RESULTS AND ANALYSIS}

To study the operation of DPC-SVM based on VF, it is implemented in Matlab/Simulink environment, as shown in Fig. (7). The main parameters: AC side voltage value $E_{m}=$ $380 \mathrm{~V}$, DC-link voltage set value $U_{d c}=650 \mathrm{~V}$, AC side filter inductance value $L=5 \mathrm{mH}$, the equivalent resistance value $R$ $=0.5 \Omega$, DC-link capacitor $C=4700 \mu F$, the PWM period is $0.0002 \mu \mathrm{s}$. The PI regulators parameters of active power $p$ and reactive power $q$ are similar: $K_{P}=8, K_{I}=0.08$. The PI regulator parameters of DC-link voltage are: $K_{P d c}=4.7$, and $K_{I d c}=0.004$. The PWM rectifier output waveforms are shown in Fig. (8).

DC-link voltage waveform is shown in Fig. (8a). It is seen that DC voltage is increased from 0 to $600 \mathrm{~V}$, less than $15 \mathrm{~ms}$ of the time; the dynamic response of this system is very fast. The voltage value is stable to $650 \mathrm{~V}$ in about $40 \mathrm{~ms}$.

Instantaneous active power and reactive power waveform is shown in Fig. (8b), in which instantaneous active power (given $4 K W$ ) is stable, reactive power fluctuates around 0 . They have good stability.
Figs. (8c) and (8d) illustrate the effect of DC side load on the operation of system. In Fig. (8c), the active power $p$ changes from $8 K W$ to $2 K W$ in about $0.1 \mathrm{~ms}$. In this time point, the rectifier state changes to the inverter state, the bidirectional flow of energy is realized and power factor is near -1 during system inverting. After this, the system is back to rectifier and stable to low active power. In Fig. (8b), the reactive power $p$ changes from $2 K W$ to $8 K W$ in about $0.1 \mathrm{~ms}$. After the transient, the system is stable to high active power.

\section{CONCLUSION}

A conventional three-phase voltage PWM rectifier involves four types of sensors: AC voltage sensors, AC current sensors, DC voltages sensors and DC current sensors. They play very important roles in direct power control on PWM rectifier. The control strategy of direct power based on virtual flux is discussed in this paper. The orientation of virtual flux is applied to the three-phase PWM rectifier direct power control. This method can not only remove the sensor of grid voltage detection, but also enhance the system's reliability. The space vector modulation is combined in the control strategy of direct power based on virtual flux.

According to the analysis of the formation mechanism of the switch table, there are 12 vectors in the stationary coordinate so as to optimize the input voltages. This method uses the estimated VF vector instead of the line voltage vector in the control. Virtual flux estimator is adopted to replace voltage sensors. Virtual flux active and reactive power are estimated by Instantaneous power theory. Space vector modelation is introduced to direct power control strategy in order to provide the fixed switching frequency on pulse-width modulation. The experimental results show that the direct power control system has good dynamic response, so as to achieve active and reactive power control, which ensures that the input side of the unity power factor is in control. It is illustrated that this method can achieve higher power factor and total lower harmonic distortion as compared to the conventional current control strategy.

\section{CONFLICT OF INTEREST}

The authors confirm that this article content has no conflict of interest

\section{ACKNOWLEDGEMENTS}

This work is supported by the National Natural Science Foundation of China (U1404512 and U1404512), the Development Plan Project of Science and Technology in Luoyang city (1401017A) and the Fostering Innovation Fund in Henan University Science and Technology (2013ZCX019).

\section{REFERENCES}

[1] J.R. Rodriguez, J.W. Dixon, J.R. Espinoza, J. Pontt, and P. Lezana, "PWM regenerative rectifiers: state of the art", IEEE Transactions Industrial Electronics, vol. 52, no. 1, pp. 5-22, 2005.

[2] A. Bouafia, J. P. Gaubert, and F. Krim, "Predictive direct power control of three-phase pulse-width modulation (pwm) rectifier using space-vector modulation (SVM)", IEEE Transactions on Power Electronics, vol. 25, no. 1, pp. 228-236, 2010. 
[3] S. Venkateshwarlu, B. P. Muni, A. D. Rajkumar, and J. Praveen, "Direct power control strategies for multilevel inverter based custom power devices", Proceedings of World Academy of Science, Engineering and Technology, vol. 29, no. 5, pp. 205-213, 2008.

[4] Y. Xingwu, and J.G. Jiangu, "Predictive direct power control for three-phase voltage source PWM rectifiers", Proceedings of the CSEE, vol. 31, no. 3, pp.34-39, 2011.

[5] H. Denoun, N. Benamrouche, S. Haddad, S. Meziani, and S. Ait Mamar, "Single-phase unity power factor unipolar pwm rectifier using DSP", International Review on Modelling and Simulations, vol. 4, no. 1, pp. 17-22, 2011.

[6] T. Wei, "A novel direct power control methodof three-phase active rectifiers in industrial drive system", Proceedings of the IEEE International Conference on Mechatronics and Automation, Harbin, China, pp. 3712-3716, August, 2007.

[7] W. Zhang, Y. Hou, and X. Liu, "Switched control of three-phase voltage ource pwm rectifier under a wide-range rapidly varying active load", IEEE Transactions on Power Electronics, vol. 27, no. 2, pp. 881-890, 2012.

[8] J. Restrepo, J. M. Aller, and J. Viola, "A simplified rectifier voltage vector election for direct power control," Proceedings of the $7^{\text {th }}$ In- ternational Caribbean Conference on Devices, Circuits and Systems, Mexico, 2008, pp. 28-30.

[9] S. R. Hadian-amrei, and H. Iranmanesh, "Novel direct power control for compensating voltage unbalance and load fluctuations in pwm rectifiers", Journal of Structural Engineering, vol. 6, no. 4, pp. 39-45, 2006.

[10] P. Cortes, J. Rodriguez, and E. Quevedo, "Predictive current control strategy with imposed load current spectrum", IEEE Transactions on Power Electronics, vol. 23, no. 2, pp. 612-618, 2008.

[11] T. Noguchi, H.Tomiki, S. Kondo and I. Takahashi, "Direct power control of pwm converter without power-source voltage sensors". IEEE Transactions Industry Applications, vol. 34, no. 3, pp. 473479, 1998.

[12] S. Chen, and G. Joos, " Direct power control of active filters with averaged switching frequency regulation", IEEE Transactions on Power Electron, vol. 23, no. 6, pp. 2729-2737, 2008.

[13] M. Malinowski, and M. P. Kazmierkowsk, "Direct power control of three phase pwm rectifier using space-vector modulation". IEEE Transactions Industrial Electronics, vol. 51, no. 2, pp. 447-454, 2004.

(C) Fan et al.; Licensee Bentham Open.

This is an open access article licensed under the terms of the Creative Commons Attribution Non-Commercial License (http://creativecommons.org/licenses/by-nc/4.0/) which permits unrestricted, non-commercial use, distribution and reproduction in any medium, provided the work is properly cited. 